\title{
COVID-19 associated sick days spike in insulin requirements: the need for rapidly escalating treatment and rapidly reducing on recovery
}

\author{
HELEN A CASEY, CHRIS KELLY \\ Department of Diabetes and Endocrinology, Forth Valley Royal Hospital, Larbert, Scotland, UK
}

We welcome correspondence and research letters to the journal.

Research letters should be no more than 800 words with a maximum of 10 references, one table and/or one figure. These will usually be short reports of interim work or final reports of research that do not warrant a full research paper publication. Letters to the editor relating to any articles published in the Journal Letters should ideally be submitted within 2 months following publication of the article on which the authors wish to comment, and should be no more than 600 words with up to 5 references
Key words: COVID-19, Diabetes Mellitus, severe acute respiratory syndrome coronavirus 2 , hyperglycaemia, diabetic ketoacidosis

Diabetes mellitus is associated with a more severe disease course for COVID-19 infection, caused by the severe acute respiratory syndrome coronavirus 2 (SARS-CoV-2). ${ }^{1}$ Hyperglycaemia and high insulin requirements have been experienced in multiple centres worldwide in patients with diabetes and COVID-19. ${ }^{2}$ Extremely large insulin requirements have been reported in the most critically ill.

We report on two cases with COVID-19 who developed significant insulin requirement which resolved rapidly as the patients recovered from the infection.

Case 1 is a 78-year-old Scottish white male with a diagnosis of type 2 diabetes mellitus admitted with COVID-19. His past medical history also included ischaemic heart disease, hypertension and obesity. He had been diagnosed with type 2 diabetes mellitus one month earlier with a $\mathrm{HbA}_{1 \mathrm{c}}$ of $102 \mathrm{mmol} / \mathrm{mol}$, body mass index $34.8 \mathrm{~kg} / \mathrm{m}^{2}$. His diabetic therapy prior to admission was metformin $1 \mathrm{~g}$ twice daily monotherapy.

When he was admitted with COVID 19 he was noted to be extremely hyperglycaemic with glucose $35.7 \mathrm{mmol} / \mathrm{L}$ and a significant inflammatory response with C-reactive protein $155 \mathrm{mg} / \mathrm{L}$. Urinary ketones were negative and $\mathrm{pH}$ was normal. He was initially treated with doses of rapid acting insulin and intravenous fluids. He was admitted for 7 days during which time he required oxygen support via nasal cannula, intravenous fluids and antibiotics. He was started on gliclazide $160 \mathrm{mg}$ twice daily and Humulin I 30 units twice daily, which kept his blood sugars within target throughout his admission. His metformin was temporarily suspended during admission due to an acute kidney injury which recovered with rehydration.
The regime of Humulin I 30 units twice daily, gliclazide $160 \mathrm{mg}$ twice daily and metformin $1 \mathrm{~g}$ twice daily was continued on discharge. He was closely followed on discharge and continued to recover at home. As his symptoms improved his glycaemic therapy requirements dramatically reduced and by 15 days post discharge his insulin had been withdrawn and his gliclazide had been reduced to $80 \mathrm{mg}$ twice daily. Blood glucose has remained controlled to date on a regimen of gliclazide $80 \mathrm{mg}$ twice daily and metformin $1 \mathrm{~g}$ twice daily.

Case 2 is a 51-year-old Scottish white male with a diagnosis of type 2 diabetes mellitus for 10 years who was admitted with COVID-19 and diabetic ketoacidosis. His past medical history included a previous renal transplant 22 years ago secondary to reflux nephropathy, His last recorded $\mathrm{HbA}_{1 c}$ was taken 4 years prior to admission at $112 \mathrm{mmol} / \mathrm{mol}$, body mass index $24.5 \mathrm{~kg} / \mathrm{m}^{2}$. His glycaemic therapy on admission was glimepiride $6 \mathrm{mg}$ and metformin $1 \mathrm{~g}$ twice daily.

He was admitted positive for COVID-19 with diabetic ketoacidosis, initial blood results showing $\mathrm{H}^{+} 50 \mathrm{nmol} / \mathrm{L}, \mathrm{pH} 7.30$, bicarbonate $19 \mathrm{mmol} / \mathrm{L}$, glucose $37.4 \mathrm{mmol} / \mathrm{L}$ and 3+ urinary ketones. Unfortunately, plasma ketones or $\mathrm{HbA}_{1 c}$ were not measured on admission. During his 3-day admission, after completing intravenous insulin for 24 hours he required Humulin I 40 units twice daily and Novorapid 15 units three times daily with meals to maintain blood glucose within target. $\mathrm{He}$ was also treated with oxygen via a nasal cannula, intravenous fluids and antibiotics. Post discharge he was followed closely and continued his recovery from COVID-19. Four days post discharge his insulin was stopped completely due to reduced requirements and hypoglycaemia. His blood glucose has remained controlled to date on glimepiride $6 \mathrm{mg}$ and metformin $1 \mathrm{~g}$ twice daily. 


\section{Discussion}

Both of these patients had large insulin requirements while unwell with COVID-19 and neither received steroids during their admissions, which supports what has been seen in other centres. 12 Our patients both had very high $\mathrm{HbA}_{1 \mathrm{c}}$ prior to admission (>100 $\mathrm{mmol} / \mathrm{mol}$ ), which may have contributed to the stress dysglycaemia and put them in a higher risk category for COVID-19 infection. Weight loss and anorexia have been associated with COVID-19 infection. Unfortunately, discharge weight was not measured in these cases but lifestyle advice was given to both patients which may have contributed to their good glycaemic control to date.

However, the large insulin requirements of 1.8 units/kg and 1.6 units $/ \mathrm{kg}$, respectively, during acute admission of these previously insulin therapy-naive patients are beyond those usually seen in other critical illnesses. Importantly, on recovery our patients experienced rapidly resolving requirements, both discontinuing insulin therapy shortly after discharge.

Large insulin requirements in patients with COVID-19 are likely to be multifactorial. Several hypotheses have been suggested to account for this large increase in insulin requirement.

COVID-19 is linked to a highly activated inflammatory response which leads to the release of stress hormones such as cortisol, increasing insulin resistance. However, the insulin requirements seen in COVID-19 seem to be above those required in other forms of critical illness associated with insulin resistance.

Mechanistic pathways have been suggested to play a role in COVID-19 infection and reduction of endogenous insulin production.

SARS-CoV-2, the causative virus of COVID-19, uses angiotensinconverting enzyme 2 (ACE2) as a receptor for the coronavirus spike protein. ${ }^{3}$ ACE2 is expressed by the pancreas on the endocrine $\beta$ cells. SARS-CoV-1 may cause acute $\beta$ cell damage directly from viral entry leading to insulin deficiency. ${ }^{4}$ The severe acute respiratory syndrome coronavirus 1 (SARS-CoV-1), which causes SARS, also uses ACE2 as a receptor. SARS-CoV-1 has been reported to cause new diabetes in more than $50 \%$ of patients during hospitalisation, ${ }^{1,4}$ with one study showing only $5 \%$ of patients remaining diabetic 3 years post infection. ${ }^{4}$

More work must be undertaken to truly understand the relationship between COVID-19 and the dramatically increased insulin requirements during this illness.

Guidelines from leading bodies such as Diabetes UK for patients with diabetes and COVID-19 highlight the need for close glucose monitoring due to the risk of hyperglycaemia and metabolic decompensation. 1,3 Our cases highlight how this increased requirement may be short-lived. During recovery, clinicians must ensure a robust follow-up and close blood glucose monitoring plan to ensure patient safety as requirements may rapidly decrease.

\section{Conflict of interest None \\ Funding None}

\section{References}

1. Bornstein ST, Rubino F, Khunti K, et al. Practical recommendations for the management of diabetes in patients with COVID-19. Lancet Diabetes Endocrinol 2020;8(6):546-50. https://doi.org/10.1016/S22138587(20)30152-2

2. Diabetes UK. Concise advice on inpatient diabetes (COVID:Diabetes): guidance for managing inpatient hyperglycaemia. 29 April 2020.

Available from: https://www.diabetes.org.uk/resources-s3/public/202004/COvID_Hyper_v4.2.pdf

3. Bindom SM, Lazartigues E. The sweeter side of ACE2: physiological evidence for a role in diabetes. Mol Cell Endocrinol 2009;302:193-202. https://doi.org/10.1016/j.mce.2008.09.020

4. Yang JK, Lin SS, Ji XJ, Guo LM. Binding of SARS coronavirus to its receptor damages islets and causes acute diabetes. Acta Diabetol 2010;47:193-9. https://doi.org/10.1007/s00592-009-0109-4

Correspondence: Dr Helen A Casey Department of Diabetes and Endocrinology, Forth Valley Royal Hospital, Larbert, Scotland FK5 4WR, UK E-mail: Helen.Casey@ggc.scot.nhs.uk.

Br J Diabetes 2020;20:166-167 https://doi.org/10.15277/bjd.2020.261 